\title{
Tobacco consumption in adolescence: Age and regional trends The Young HUNT Study, Norway (1995-2008)
}

\author{
Håvard Thoen and Turid Lingaas Holmen \\ HUNT Research Centre, Department of General Practice and Public Health, Faculty of Medicine, \\ Norwegian University of Science and Technology \\ Correspondence: Håvard Thoen, HUNT forskningssenter, Forskningsveien 2, 7600 Levanger E-mail: havard.thoen@ntnu.no
}

\begin{abstract}
Background: The aim of this study was to describe the trends of smoking and snuff consumption in adolescents in Nord-Trøndelag, Norway, in the period from 1995/97 to 2006/08, with special emphasize on regional and gender differences.

Method: We used data from all three waves of the Young-HUNT study, the youth part (ages 13-19 yrs) of the HUNT study, Nord- Trøndelag County, Norway. Young-HUNT 1 was conducted in 1995-97 (N=9131, $90 \%$ response rate), Young-HUNT 2 in 1999-2000 ( $\mathrm{N}=2808,80 \%$ response rate) and Young-HUNT 3 in 2006-08 (N=8601).

Results: Fewer adolescents had tried smoking in Young-HUNT 3 (40.6\%) compared to Young-HUNT 1 $(56.5 \%)$, while the prevalence of adolescents who had tried snuff increased in the same period from $17.4 \%$ to $23.5 \%$. The prevalence of adolescents who smoked daily or occasionally decreased between YoungHUNT 1 (girls 23.8\%, boys 19.8\%) and Young-HUNT 3 (girls: 14.6\%, boys: 12.1\%), while the prevalence of daily or occasionally snuffing increased (girls: $3.4 \%$ to $13.0 \%$ and boys: $20.2 \%$ to $23.1 \%$ ). This constitutes a fourfold increase of the number of young female snuff users in little more than a decade. Occasional snuff use increased most in girls while daily snuff use increased most in boys. The same tendency was seen inn all regions, but the prevalence of tobacco use varied.

Conclusion: The results demonstrate a shift from cigarette smoking to snuff use in the adolescent population between 1995 and 2008. Although a decrease in cigarette smoking occurred, the increasing snuff use makes the total tobacco consumption nearly constant.
\end{abstract}

\section{INTRODUCTION}

No other lifestyle factor has the same amount of documented, extensive health effects as smoking, being one of the most important factors leading to preventable, early loss of life. Smoking is the most important cause of lung cancer and COPD, one of the main causes of cardiovascular diseases and an important cause also of other cancer types (1). It is estimated that in 2003, $16 \%$ of all deaths in Norway were caused by smoking, and $19 \%$ of all deaths in the age group below 75 years (1). Thus, an important goal in Norway has been to prevent young people from starting and maintaining smoking.

Data from Statistics Norway (SSB) has revealed that cigarette smoking among Norwegians has been strongly reduced in recent decades in accordance with implementations of new laws and regulation against smoking (2). In 1973, 45\% of adolescents and young adults (aged 16-24) smoked daily, while in the beginning of the 1980 s the prevalence had decreased to about $30 \%$. During the next twenty years little changed, and daily smoking in this age group remained approximately $30 \%$. However, during the last ten years, and especially after the introduction of the law against smoking in restaurants of 2004, daily smoking has decreased rapidly again $(2,3)$. Smoking has also been reported to decrease in Norwegian middle school students after year 2000 (4).
As smoking has decreased, the average age when people in Norway start to smoke daily also seems to have decreased. Daily smokers born in 1960-69 started to smoke daily just before they turned 18 years of age, on average, while daily smokers born in 1980-89 started to smoke daily before they turned 16 years (5).

Ability to quit smoking might also be important in smoking reduction, but quitting smoking has been shown to be hard. $70 \%$ of smokers say they would like to quit, and every year $40 \%$ manage to quit for at least one day. $80 \%$ of those who attempt to quit on their own, return to smoking within a month, and each year, only $3 \%$ of smokers quit successfully (6).

Paralell to the decrease in smoking, an increase in snuff use has been reported in both middle school students (4) and in older teenagers (3). The increase seems to have been strongest from year 2000 and among girls. Very few girls used snuff before year 2000.

While the health effects of smoking are well documented, the health effects of snuff use are still under debate. Snuff has been reported to increase the risks of pancreatic, oesophageal and gastric cancer, lethal heart infarction, lethal stroke and elevated blood pressure (7). Snuff might have high concentration of nicotine effectively transported into the blood stream. This may be of importance as there is demonstrated interaction between nicotine and other drugs in the brain's reward system (7). In a Swedish study (8) of adolescents the annual consumption of alcohol was five to ten times 
higher among tobacco users than among nonusers, and snuff users consumed even more alcohol than smokers.

Regional differences between Norwegian counties have been reported both for cigarette use and snuff use among 16-24-year-olds (5). Smoking has been found to have a socioeconomic gradient, as adolescents with a lower socioeducational status were much likelier to be smoking compared to those with higher socioeducational status (9). This is supported by the findings of Grøtvedt et al., who found than young students who planned vocational classes were more likely to be daily smokers compared to students planning to study in academic classes (10). However, no association between socioeducational status and snuff use was found (9).

Altough Norwegian studies have documented a decrease in smoking prevalence and an increase in snuff use among adolescents, few have focused on the combined tobacco use over time, regional differences within a county and trends in debut age and quitting rate.

The aims of this paper were to study trends in tobacco use among adolescents using data from the Young-HUNT study, Nord-Trøndelag County, Norway, with emphasize on regional and gender differences and changes in debut age and quitting rate during a tenyear period.

\section{METHODS}

Young-HUNT is the youth part of the Nord-Trøndelag Health Study, conducted in Nord-Trøndelag County, Norway (www.ntnu.hunt.no). Young-HUNT consists of three separate surveys. Young-HUNT 1 was conducted in 1995-97, Young-HUNT 2 in 1999-2000 and YoungHUNT 3 in 2006-08. Young-HUNT 1 and YoungHUNT 3 included adolescents aged 13-19 years. Young-HUNT 2 was a follow-up study of YoungHUNT 1 and included only adolescents aged 16-19 years at the time.

\section{Setting}

Each Young-HUNT survey consisted of a questionnaire, interviews and clinical measurements. The selfadministered questionnaire was completed during one school hour, in a setting like an exam with no opportunity to view answers of other students. All HUNT data are linked to the unique 11-digit personal identification number enabled every Norwegian citizen at birth or immigration. The questionnaires, however, were coded and with no names. The students put the completed questionnaire in a blank envelope and sealed it themselves. Within a month after completing the questionnaire, participants were invited to a clinical examination performed by specially trained project nurses who visited every school. The Young-HUNT study was approved by The Regional Committee for Medical and Health Research Ethics (REK) in MidNorway and the Data Inspectorate.

In this study we used only data from the questionnaires, including 8984 participants $(89 \%)$ in YoungHUNT 1, 2808 (80\% of the invited) participants in
Young-HUNT 2 and $8200(80 \%)$ participated in Young-HUNT 3.

\section{Variables}

In this paper we have used two questions related to smoking and one question related to snuff use, which were asked in all three surveys of the Young-HUNT study. The first question related to smoking was "Have you ever tried smoking? (Yes/No). If respondents gave a positive response, they were asked to answer the follow-up question "Do you smoke now?" The response alternatives were: 1 'Yes, I smoke daily', 2 'Yes, I smoke occasionally, but not daily', 3 'No, but earlier I smoked occasionally', 4 'No, but earlier I smoked daily' and 5 'No, I don't smoke.' Respondents who smoked or had smoked daily were asked how many cigarettes they smoked daily. Daily smoking was defined as 'Yes, I smoke daily' and occasional smoking as 'Yes, I smoke occasionally, but not daily'.

Respondents were also asked: "Do you use or have you used snuff, chewing tobacco or similar?" Response alternatives were 1 'No, never', 2 'Yes, but I have quit', 3 'Yes, occasionally' and 4 'Yes, every day'. The prevalence of ever tried snuff was estimated by constructing a new variable where those who answered 'No, never' were given 0 , and all other alternatives were given 1 , since these alternatives implicitly meant they had tried using snuff. Occasional snuff use and daily snuff use were coded accordingly.

Individuals reporting that they smoked occasionally or daily were considered "current smokers" and respondents reporting that they used snuff occasionally or daily were considered "current snuff users".

In Young-HUNT 3 another two questions were added: "If you use or have used both cigarettes and snuff, what did you start with first?" and "Did you start using snuff to stop or reduce smoking?"

In the analyses Nord-Trøndelag County was divided into regions between rural and more densely populated areas, allowing comparisons. Steinkjer-Inderøy, Verdal, Levanger-Frostad, Meråker-Stjørdal and Middle Namdal were defined as regions with cities or more densely populated areas.

Age was estimated using month and year of birth and date of survey participation. Average age in Young-HUNT 1 was 16.0 years, in Young-HUNT 2 18.3 years and in Young-HUNT 315.9 years. Age was categorized into two groups; $13-15$ years and 16-19 years. A small number of respondents aged 12 or 20 years were excluded from the analyses.

All statistics were conducted using STATA 10.1 for Windows.

\section{RESUlts}

Adolescent current smoking decreased, while current snuff use increased from Young-HUNT 1 (1995-97) to Young-HUNT 3 (2006-08). This was the case in both sexes and in all age groups, except snuff use in boys aged 13 and 14 (Fig. 1). 

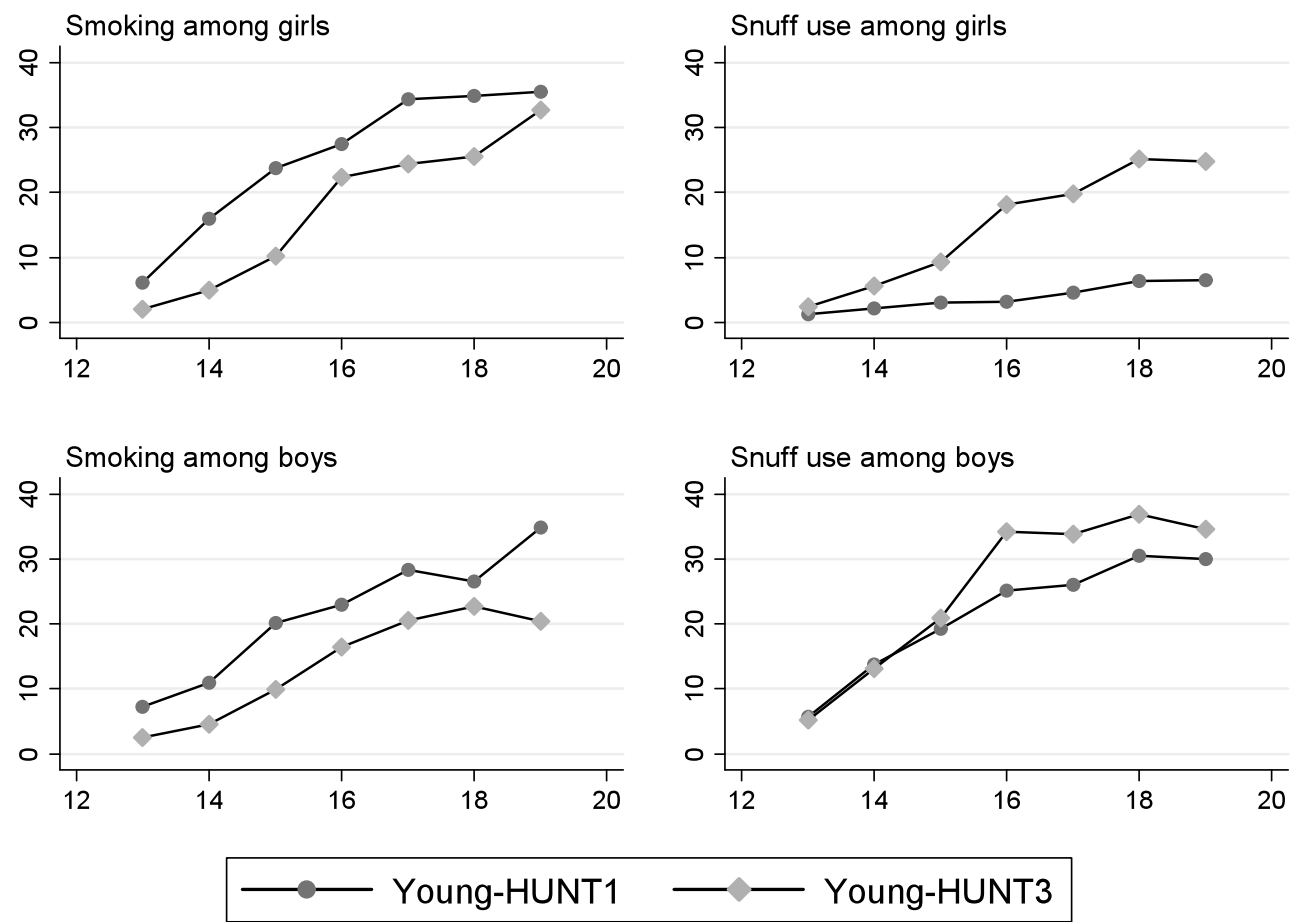

Figure 1. Daily or occasionally smoking (\%) and use of snuff (\%) among boys and girls aged 13-19 years in Young-HUNT 1 (1995-97) and Young-HUNT 3 (2006-08).

\section{Cigarette smoking}

In Young-HUNT 1 (1995-97) nearly half (48.9\%) of girls in the youngest age group had tried smoking, while eleven years later only $25.7 \%$ reported having tried smoking. Among the oldest girls there was an increase from $67.3 \%$ in Young-HUNT 1 to $77.0 \%$ in Young-HUNT 2 (2001-03), but from Young-HUNT 2 to Young-HUNT 3 (2006-08) there was a decrease of those who had tried smoking to $59.2 \%$ (Table 1). The same tendency was seen in boys where the prevalence of having tried smoking decreased from Young-HUNT $1(45 \%)$ to Young-HUNT $3(27 \%)$ in the youngest age group and from $65 \%$ to $55 \%$ in the oldest age group (Table 2). Also boys in the oldest age group reported the highest prevalence (71.3\%) in Young-HUNT 2.

Current smoking (daily or occasionally) decreased in both sexes and both age groups from Young-HUNT 1 to Young-HUNT 3 (Tables 1 and 2). The decline was most pronounced in the youngest age groups, but smoking remained fairly high in the oldest age groups, especially among girls. When comparing Young-HUNT 1 and Young-HUNT 3, the prevalence of daily smokers also decreased (Tables 1 and 2). In the total population (13-19 years) daily smokers were reduced from $11.4 \%$ to $7 \%$ in girls and from $9.6 \%$ to $6.2 \%$ in boys.

The debut age of daily smoking was 13.9 years and did not change from Young-HUNT 1 to Young-HUNT 3. Among those who reported having tried smoking, the proportion who said they had been daily smokers, but quitted smoking later, was similar in Young-HUNT 1 (3.6\%) and Young-HUNT 3 (3.9\%). However, the proportion of quitters among occasional smokers was statistically significant higher in Young-HUNT 3 (10.6\%) compared to Young-HUNT 1 (9.0\%).

\section{Snuff use}

In Young-HUNT $13.2 \%$ of girls in the youngest age group had tried snuff, compared to $8.2 \%$ in YoungHUNT 3, while in the oldest age group $6.6 \%$ of girls had tried snuff in Young-HUNT 1 compared to $25 \%$ in Young-HUNT 3 (Table 1). In the oldest age group this represents more than a threefold increase of the prevalence of having tried snuff. The prevalence of the oldest girls who reported current daily or occasionally snuffing increased even more; from $4.7 \%$ in YoungHUNT 1 to $21.1 \%$ in Young-HUNT 3. Most of the increase was due to increase in occasional snuff use.

In boys aged 13-15 the prevalence of having tried snuff was $19.8 \%$ in Young-HUNT 1 compared to $21.9 \%$ in Young-HUNT 3 (Table 2). In the oldest age group (16-19 years) $34.7 \%$ had tried snuff in YoungHUNT 1 compared to $42.0 \%$ in Young-HUNT 3. Current snuff use in the youngest boys remained nearly constant; $13.2 \%$ in Young-HUNT 1 vs. $13.6 \%$ in Young-HUNT 3. In Young-HUNT 1 the prevalence of daily snuffing was $2.6 \%$ in boys aged $13-15$ and $8.3 \%$ in the age group 16-19 years, compared to $4.8 \%$ and $19.2 \%$ in Young-HUNT 3, which constitutes a twofold increase in both age groups. Opposite to girls the highest increase in boys was in daily use of snuff.

\section{Smoking and snuff use combined}

Most adolescents who reported snuff use had also tried smoking. In Young-HUNT 1 only $14.5 \%$ of occasional and $11.6 \%$ of daily snuff users had never tried smok- 
Table 1. Prevalence of smoking, snuff use and mixed tobacco consumption among girls aged 13-19 years who participated in the YOUNG-HUNT Study, 1995/97 to 2006/08.

\begin{tabular}{|c|c|c|c|c|c|c|c|c|c|c|c|c|}
\hline \multirow{3}{*}{$\begin{array}{l}\text { Question and } \\
\text { respondent } \\
\text { age (years) }\end{array}$} & \multicolumn{4}{|c|}{ Young-HUNT 1} & \multicolumn{4}{|c|}{ Young-HUNT 2} & \multicolumn{4}{|c|}{ Young-HUNT 3} \\
\hline & \multirow{2}{*}{$\begin{array}{c}\text { Total } \\
\text { no. }\end{array}$} & \multicolumn{3}{|c|}{ Yes } & \multirow{2}{*}{$\begin{array}{c}\text { Total } \\
\text { no. }\end{array}$} & \multicolumn{3}{|c|}{ Yes } & \multirow{2}{*}{$\begin{array}{c}\text { Total } \\
\text { no. }\end{array}$} & \multicolumn{3}{|c|}{ Yes } \\
\hline & & No. & $\%$ & $\mathrm{CI}$ & & No. & $\%$ & $\mathrm{CI}$ & & No. & $\%$ & $\mathrm{CI}$ \\
\hline \multicolumn{13}{|c|}{ Ever tried smoking? } \\
\hline $13-15$ & 2205 & 1079 & 48.9 & $(46.83,51.04)$ & & & & & 2136 & 549 & 25.7 & $(23.86,27.61)$ \\
\hline $16-19$ & 2087 & 1405 & 67.3 & $(65.26,69.33)$ & 1393 & 1072 & 77.0 & $(74.65,79.14)$ & 1884 & 1116 & 59.2 & $(56.98,61.47)$ \\
\hline \multicolumn{13}{|c|}{ Current smoking (daily or occasionally)? } \\
\hline $13-15$ & 2209 & 348 & 15.8 & $(14.25,17.34)$ & & & & & 2137 & 124 & 5.8 & $(4.85,6.88)$ \\
\hline 16-19 & 2090 & 675 & 32.3 & $(30.29,34.35)$ & 1393 & 571 & 41.0 & $(38.93,43.63)$ & 1886 & 463 & 24.6 & $(22.62,26.56)$ \\
\hline \multicolumn{13}{|c|}{ Daily smoking? } \\
\hline $13-15$ & 2205 & 133 & 6.0 & $(5.07,7.11)$ & & & & & 2136 & 48 & 2.2 & $(1.66,2.97)$ \\
\hline $16-19$ & 2087 & 407 & 19.5 & $(17.82,21.26)$ & 1393 & 328 & 23.6 & $(21.34,25.86)$ & 1885 & 236 & 12.5 & $(11.06,14.10)$ \\
\hline \multicolumn{13}{|c|}{ Ever tried snuff? } \\
\hline $13-15$ & 2226 & 72 & 3.2 & $(2.54,4.06)$ & & & & & 2161 & 178 & 8.2 & $(7.11,9.48)$ \\
\hline $16-19$ & 2089 & 138 & 6.6 & $(5.58,7.76)$ & 1388 & 100 & 7.2 & $(5.90,8.69)$ & 1897 & 475 & 25.0 & $(23.10,27.05)$ \\
\hline \multicolumn{13}{|c|}{ Current snuff use (daily or occasionally)? } \\
\hline $13-15$ & 2226 & 49 & 2.2 & $(1.63,2.90)$ & & & & & 2161 & 126 & 5.8 & $(4.88,6.90)$ \\
\hline 16-19 & 2089 & 99 & 4.7 & $(3.87,5.74)$ & 1388 & 77 & 5.5 & $(4.40,6.89)$ & 1897 & 400 & 21.1 & $(19.27,22.99)$ \\
\hline \multicolumn{13}{|c|}{ Daily snuff use? } \\
\hline $13-15$ & 2226 & 1 & 0 & $(0,0.25)$ & & & & & 2161 & 12 & 0.6 & $(0.29), 0.97)$ \\
\hline $16-19$ & 2089 & 6 & 0.3 & $(0.10,0.62)$ & 1388 & 9 & 0.7 & $(0.29,1.23)$ & 1897 & 62 & 3.3 & $(2.51,4.17)$ \\
\hline \multicolumn{13}{|c|}{ Tried both snuff and smoking? } \\
\hline $13-15$ & 2239 & 68 & 3.0 & $(2.37,3.83)$ & & & & & 2163 & 145 & 6.7 & $(5.69,7.84)$ \\
\hline $16-19$ & 2088 & 119 & 5.7 & $(4.74,6.78)$ & 1390 & 90 & 6.5 & $(5.24,7.90)$ & 1898 & 382 & 20.1 & $(18.34,22.00)$ \\
\hline \multicolumn{13}{|c|}{ Current mixed tobacco use (daily or occasionally)? } \\
\hline $13-15$ & 1883 & 22 & 1.2 & $(0.73,1.76)$ & & & & & 2164 & 45 & 2.1 & $(1.52,2.77)$ \\
\hline $16-19$ & 1474 & 59 & 4.0 & $(3.06,5.13)$ & 1392 & 46 & 3.3 & $(2.43,4.38)$ & 1900 & 183 & 9.6 & $(8.34,11.05)$ \\
\hline
\end{tabular}

ing, while in Young-HUNT $322.7 \%$ of occasional and $8.1 \%$ of daily snuff users had never tried smoking.

More current smokers reported simultaneously snuff use, especially among boys (girls: $36.3 \%$ aged $13-15$ years and $39.5 \%$ aged $16-19$ years and boys: $70.4 \%$ aged $13-15$ years and $72.3 \%$ aged $16-19$ years), compared to the proportion of current snuff users who reported also to smoke (girls: $35.7 \%$ aged $13-15$ years and $45.8 \%$ aged $16-19$ years and boys: $29.6 \%$ aged $13-$ 15 years and $40.1 \%$ aged $16-19$ years) However, of the total population, few boys and girls reported to have a current mixed tobacco use, that is being both current smokers and current snuff users (Tables 1 and 2).

In HUNT 3, most of the boys (63\%) who reported that they used or had used both snuff and cigarettes reported to have started with snuff before starting to smoking. On the contrary, most girls (57\%) had started smoking before snuffing. Only $18.5 \%$ of snuff users in Young-HUNT 3 responded that they had started using snuff to stop or reduce their smoking.

The overall prevalence of adolescents who currently used some kind of tobacco product (smoked and/or used snuff) seemed to have remained almost stable from Young-HUNT 1 to Young-HUNT 3, with a decreasing tendency in the youngest age group (girls: $17 \%$ to $9 \%$, boys: $20 \%$ to $16 \%$ ), but an increased tendency in the oldest age group (girls: $33 \%$ to $36 \%$, boys: $26 \%$ to $41 \%$ ).

\section{Regional differences}

The percentage of adolescents who smoked currently varied between regions, but a decrease between Young-HUNT 1 and Young-HUNT 3 was seen in all regions (Fig. 1). The largest decrease was seen in regions with cities or more densely populated areas, except for Verdal.

Snuff use increased in all regions, but the same pattern between regions found in smoking was not seen (Fig. 2). The difference between the region with the highest and lowest snuff use in Young-HUNT 3 was larger than for smokers.

\section{Discussion}

In accordance with previous studies (2-4), this study demonstrates that the prevalence of smoking in Norwegian adolescence is rapidly decreasing, while the prevalence of snuffing is increasing among both boys and girls. However, the prevalence of adolescents currently using some kind of tobacco product, either snuff or smoke, daily or occasionally, had increased among 16-19-year-old boys and girls. Snuff use is now more common among boys and as common among girls compared to smoking. The same tendency was seen in all regions, but the prevalence of tobacco use varied. 
Table 2. Prevalence of smoking, snuff use and mixed tobacco consumption among boys aged 13-19 years who participated in the YOUNG-HUNT Study, Nord-Trøndelag County, Norway 1995-2008.

\begin{tabular}{|c|c|c|c|c|c|c|c|c|c|c|c|c|}
\hline \multirow{3}{*}{$\begin{array}{l}\text { Question and } \\
\text { respondent } \\
\text { age (years) }\end{array}$} & \multicolumn{4}{|c|}{ Young-HUNT 1} & \multicolumn{4}{|c|}{ Young-HUNT 2} & \multicolumn{4}{|c|}{ Young-HUNT 3} \\
\hline & \multirow{2}{*}{$\begin{array}{c}\text { Total } \\
\text { no. }\end{array}$} & \multicolumn{3}{|c|}{ Yes } & \multirow{2}{*}{$\begin{array}{c}\text { Total } \\
\text { no. }\end{array}$} & \multicolumn{3}{|c|}{ Yes } & \multirow{2}{*}{$\begin{array}{c}\text { Total } \\
\text { no. }\end{array}$} & \multicolumn{3}{|c|}{ Yes } \\
\hline & & No. & $\%$ & $\mathrm{CI}$ & & No. & $\%$ & CI & & No. & $\%$ & $\mathrm{CI}$ \\
\hline \multicolumn{13}{|c|}{ Ever tried smoking? } \\
\hline $13-15$ & 2164 & 979 & 45.2 & $(43.13,47.37)$ & & & & & 2132 & 578 & 27.1 & $(25.23,29.05)$ \\
\hline $16-19$ & 2136 & 1394 & 65.3 & $(63.20,67.28)$ & 1204 & 858 & 71.3 & $(68.61,73.81)$ & 1755 & 972 & 55.4 & $(53.02,57.73)$ \\
\hline \multicolumn{13}{|c|}{ Current smoking (daily or occasionally)? } \\
\hline $13-15$ & 2164 & 281 & 13.0 & $(11.60,14.47)$ & & & & & 2132 & 125 & 5.9 & $(4.90,6.95)$ \\
\hline $16-19$ & 2139 & 570 & 26.6 & $(24.8,28.6)$ & 1204 & 383 & 31.8 & $(29.19,34.52)$ & 1759 & 346 & 19.7 & $(17.84,21.61)$ \\
\hline \multicolumn{13}{|c|}{ Daily smoking? } \\
\hline $13-15$ & 2164 & 150 & 6.9 & $(5.90,8.08)$ & & & & & 2132 & 53 & 2.5 & $(1.87,3.24)$ \\
\hline $16-19$ & 2136 & 332 & 15.5 & $(14.03,17.15)$ & 1204 & 328 & 15.9 & $(13.84,18.05)$ & 1756 & 172 & 9.8 & $(8.44,11.28)$ \\
\hline \multicolumn{13}{|c|}{ Ever tried snuff? } \\
\hline $13-15$ & 2189 & 433 & 19.8 & $(18.13,21.51)$ & & & & & 2189 & 479 & 21.9 & $(20.17,23.67)$ \\
\hline 16-19 & 2150 & 746 & 34.7 & $(32.68,36.75)$ & 1211 & 499 & 41.2 & $(38.42,44.04)$ & 1793 & 753 & 42.0 & $(39.70,44.32)$ \\
\hline \multicolumn{13}{|c|}{ Current snuff use (daily or occasionally)? } \\
\hline $13-15$ & 2189 & 290 & 13.2 & $(11.85,14.75)$ & & & & & 2189 & 297 & 13.6 & $(12.16,15.07)$ \\
\hline $16-19$ & 2150 & 586 & 27.3 & $(25.38,29.19)$ & 1211 & 394 & 32.5 & $(29.90,35.26)$ & 1793 & 624 & 34.8 & $(32.60,37.06)$ \\
\hline \multicolumn{13}{|c|}{ Daily snuff use? } \\
\hline $13-15$ & 2189 & 57 & 2.6 & $(1.98,3.36)$ & & & & & 2189 & 105 & 4.8 & $(3.94,5.78)$ \\
\hline $16-19$ & 2150 & 179 & 8.3 & $(7.19,9.57)$ & 1211 & 194 & 16.0 & $(14.0,18.21)$ & 1793 & 344 & 19.2 & $(17.39,21.09)$ \\
\hline \multicolumn{13}{|c|}{ Tried both snuff and smoking? } \\
\hline $13-15$ & 2201 & 358 & 16.3 & $(14.75,17.87)$ & & & & & 2180 & 340 & 15.6 & $(14.10,17.19)$ \\
\hline $16-19$ & 2141 & 643 & 30.0 & $(28.09,32.02)$ & 1210 & 442 & 36.5 & $(33.81,39.31)$ & 1778 & 606 & 34.1 & $(31.88,36.34)$ \\
\hline \multicolumn{13}{|c|}{ Current mixed tobacco use (daily or occasionally)? } \\
\hline $13-15$ & 2010 & 127 & 6.3 & $(5.29,7.47)$ & & & & & 2196 & 88 & 4.0 & $(3.23,4.91)$ \\
\hline $16-19$ & 1834 & 265 & 14.4 & $(12.87,16.14)$ & 1212 & 199 & 16.4 & $(14.38,18.63)$ & 1785 & 250 & 14.0 & $(12.43,15.70)$ \\
\hline
\end{tabular}

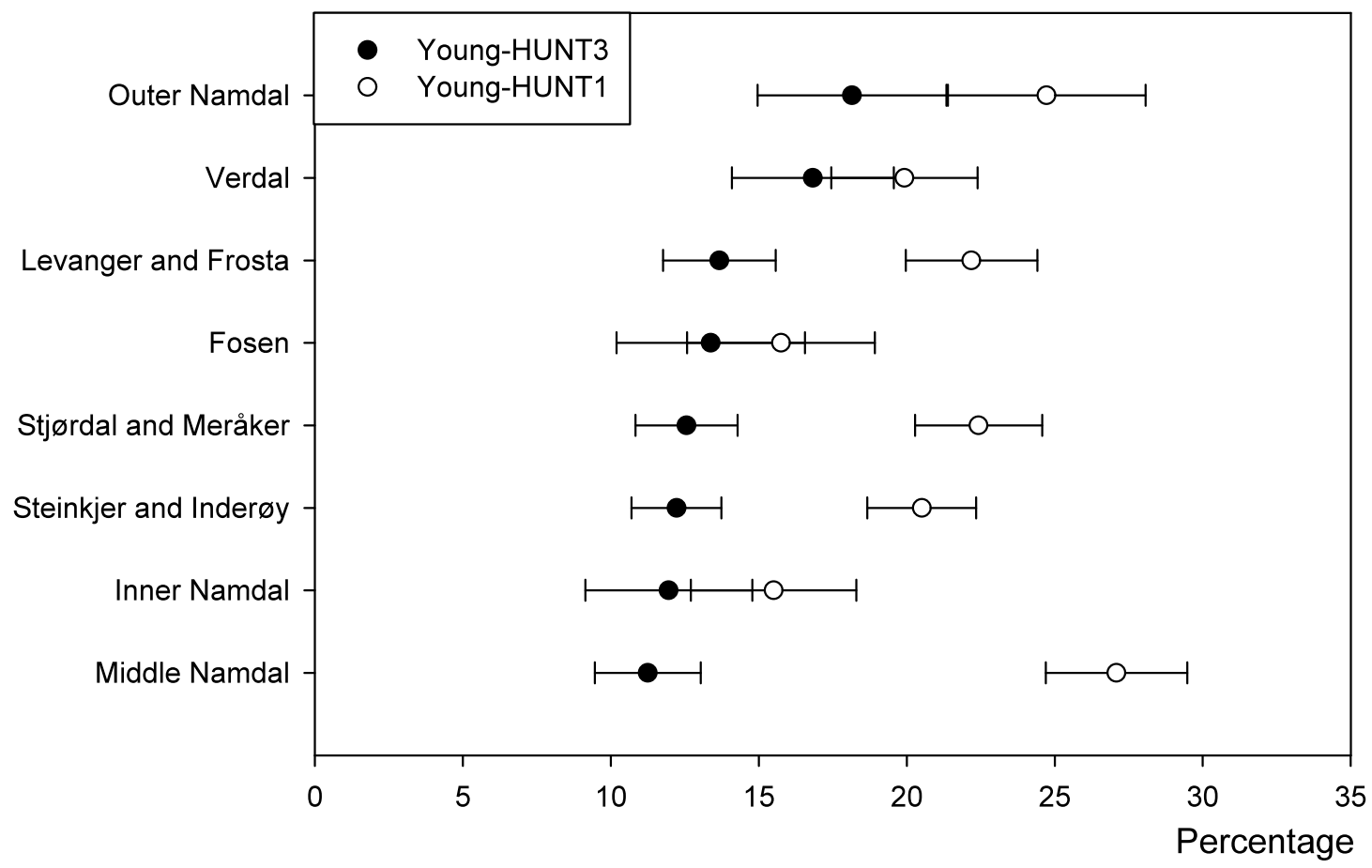

Figure 2. Percentage of adolescents in each region who smoked daily or occasionally in Young-HUNT 1 and Young-HUNT 3, whiskers show $95 \%$ confidence intervals. 


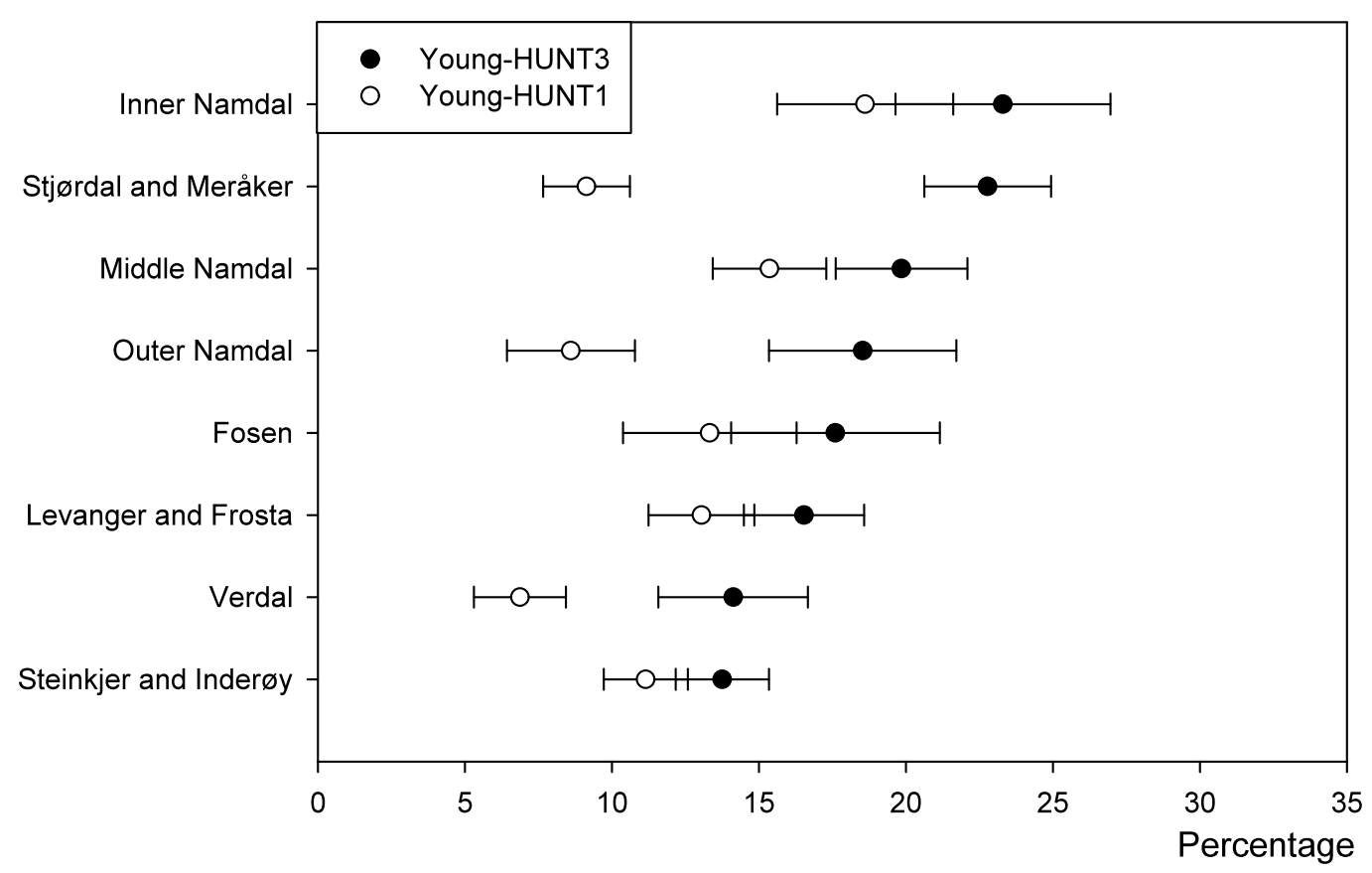

Figure 3. Percentage of adolescents in each region who used snuff daily or occasionally in Young-HUNT 1 and Young-HUNT 3, whiskers show 95\% confidence intervals.

It has been debated whether snuff use could be a gateway to smoking $(11,12)$. It is therefore interesting to notice that the majority of girls who had used both snuff and who smoked had started with cigarettes, while the majority of boys had started with snuff. Also more smokers were at the same time also snuff users compared to snuff users who simultaneously smoked. Rossow et al. (13) reported a lower proportion of smokers who also used snuff in a similar age group (13-17 year) in 2004. The whole age group and both genders were included in the estimate in that study, but it may also support the increasing popularity of snuff use, especially among boys.

In Young-HUNT the mean debut age of daily smoking was low and had not changed from 1995/97 to $2006 / 08$. These differences from the findings by Helleve et al. (5) may be due to differences in the age groups compared. It indicates, however, that in spite of the reduction in smoking prevalence, smokers still start at a very young age. The proportion of daily smokers who reported to have quitted smoking was low and did not change, as might be expected, but slightly more occasional smokers had managed to quit. This may contribute to the reduction in smoking. Only a small percentage of the adolescents had used snuff to stop or reduce smoking.

\section{Strengths and limitations}

One strength of the Young-HUNT studies is the design, aiming at including the total teenage population in Nord-Trøndelag County. The response rates in all three rounds of Young-HUNT were high, and the sample sizes quite large, indicating precise estimates.
All self-reported information may be influenced by the truthfulness of the respondents. However, some features in the design of this study foster truthful reporting, confidentiality was stressed and no names were attached to the questionnaire (14). Tobacco use was only one part of comprehensive questionnaires.

Though the overall response rate was high, results from adolescents of some specific ages should be interpreted with care. The few 12 -year-olds and 20 -yearolds who were registered in the study were excluded because they were not the target group of this study. In Young-HUNT 2 only few 16-year-olds attended, thus results for 16-year-olds in Young-HUNT 2 should be interpreted with caution. Since the 19-year-olds who had graduated from school were not invited, the total attendance rate of 19-year-olds was low in all three rounds. Most of the respondents attended school; the response rate in those not in the school system was low. It seems likely that the estimated prevalence of smoking and perhaps snuff use would be higher if we had been able to include individuals not attending school. Some events of key variables were uncommon (e.g., daily smoking in the youngest age group). Some respondents who identify themselves as occasional smokers could in fact be daily smokers.

\section{Changes in tobacco use}

The observation of the combined smoking reduction with increased snuff use, makes it prudent to ask whether the smoking reduction constitutes a real decrease in tobacco consumption, or if we instead see a shift from smoking to snuff use.

Smoking is strictly regulated in Norway. Tobacco 
products can no longer be displayed in shops, they have to be stored hidden from view. Smoking in restaurants, bars and nightclubs have not been allowed since 2004. While the youngest teenagers in YoungHUNT 3 were too young to be affected by this, it is likely to have had an indirect impact on adolescent smoking through a decline in young adults smoking. Smoking regulations have made it impossible or very hard to smoke in most social settings. Compared to smoking it is easier to use snuff, since one could use snuff where it is prohibited to smoke (4). This possible shift from smoking to snuff could be an unwanted consequence of the changes in tobacco legislation. Snuff is likely to be less harmful than smoking, yet on the other hand, we now have two different problems to address, adolescent smoking and adolescent snuff use, instead of just one. Snuff is harder to regulate, since it does not harm other persons the same way smoking does. It could be even harder to quit using snuff than smoking, since it can be used almost everywhere. Little is known about long time effects of snuff use started at very young age.

According to Lund et al. (15), the characteristics of smokers suggest that the most extensive use of tobacco is expiring. Smoking, as a phenomenon, seems to leave the Norwegian society in the same social order as it entered nearly hundred years ago. It was introduced and used in the higher social classes in the beginning, and today daily smoking has been reported to be more common among adolescents planning vocational education (10). The regional differences found in the present study may support this, where smoking is more prevalent in rural compared to urban areas. One may speculate if the same pattern will be seen in relation to snuff use. Socioeducational differences found in smoking have not been reported among Norwegian snuff users (9). It is also worth noticing that the highest prevalence of snuff use was found in regions close to the Swedish border, supporting the importance of price and availability.

The increase in snuff use among girls might be surprising, considering the stigma which has previously been connected to female snuff use. Snuff has previously been described as a male phenomenon. However, when smoking was becoming more popular at the beginning of the last century, female smoking was also considered something of a vulgarity. It could seem like history repeats itself. An interpretation of the results could be that girls' snuff use is mirroring boys' snuff use with about a ten year time lag. If this is indeed the case we should expect to see even more girls who try snuff, and that more girls who use snuff occasionally will become daily snuff users.

From an adolescent perspective snuff has several benefits compared to cigarettes. People don't smell as much after using snuff as after smoking, or at least, other people don't show the same kind of distaste. The lack of smell after using snuff makes it easier for adolescents to hide their tobacco use from parents, teacher and other adults. Tobacco companies have differentiated snuff to meet the demands of new customer groups. Earlier, the typical perception of snuff use was big, masculine boxes, a bulging over lip, and tobaccostained teeth (3). Now, snuff can be bought in little, pink or purple boxes and several portion sizes. New types of white portion snuff does not stain the teeth as much when used, as other snuff types, which also makes it easier to hide the tobacco use compared to smoking. Snuff can be used indoors and other places where smoking is prohibited. The smallest snuff portions could possibly be used without teachers or parents noticing, in the class room or at home.

\section{Implications}

The rapid increase in snuff consumption in Norway emphasizes the importance of increased research into the long-term health effects of snuff. Snuff has not been an emphasized part of tobacco prevention in Norway. This paper is in line with others that strongly suggest snuff use is rapidly increasing and the question remains how long we should wait before intensifying prevention of snuff use. As the decision about what to do about snuff is postponed, the consequence could be a missed opportunity for primary prevention.

\section{REFERENCES}

1. Vollset S, Selmer R, Tverdal A (2006). Hvor dødelig er røyking? Rapport om dødsfall og tapte leveår som skyldes røyking. Oslo: Nasjonalt folkehelseinstitutt.

2. SSB (2010). Nordmenns røykevaner 2009, from http://www.ssb.no/royk/.

3. Øverland S, Hetland J, Aarø L (2008). Røyking og snuffbruk blant ungdommar i 2004 og 2007. Tidsskr Nor Legeforen, 128, 1820-1824.

4. Aarø L, Lindbak R, Øverland S, Hetland J (2008). Tobakksbruk blant norske ungdomsskoleelever 19752005. Tidsskr Nor Legeforen, 128, 1815-1819.

5. Helleve A, Weisæth AH, Lindbak R (2010). Tall om tobakk 1973-2009. Rapport, Oslo: Helsedirektoratet (www.helsedirektoratet.no/vp/multimedia/archive/00318/Tal_om_tobakk_1973_318239a.pdf).

6. Benowitz NL (2010). Nicotine addiction. N Engl J Med, 362 (24), 2295-2303.

7. Holm L-E, Fisker J, Larsen B-I, Puska P, Halldórsson M (2009). Snuff does not save lives: quitting smoking does! Tobacco Control, 18 (4), 250-251. 
8. Wickholm S, Galanti MR, Söder B, Gilljam H (2003). Cigarette smoking, snuff use and alcohol drinking: coexisting risk behaviours for oral health in young males. Community Dent Oral Epidemiol, 31 (4), $269-274$.

9. Øverland S, Tjora T, Hetland J, Aarø LE (2010). Associations between adolescent socioeducational status and use of snuff and smoking. Tobacco Control, 19 (4), 291-296.

10. Grøtvedt L, Stigum H, Hovengen R, Graff-Iversen S (2008). Social differences in smoking and snuff use among Norwegian adolescents: a population based survey. BMC Public Health, 8, 322.

11. Melikian AA, Hoffmann D. Smokeless tobacco: a gateway to smoking or a way away from smoking. Biomarkers 2009; 14 (Suppl 1): 85-89.

12. Rodu B, Cole P. Evidence against a gateway from smokeless tobacco use to smoking. Nicotine Tob Res 2010; 12 (5): 530-534.

13. Rossow I, Pedersen W, Lund KE (2010). Kjøp av tobakk blant mindreårige. Tidsskr Nor Legeforen, 130, 1337-1339.

14. Holmen TL, Barrett-Connor E, Holmen J, Bjermer L. Health problems in teenage daily smokers versus nonsmokers, Norway, 1995-1997: the Nord-Trøndelag Health Study. Am J Epidemiol 2000; 151 (2):148-155.

15. Lund KE, Lund M (2005). Røyking og sosial ulikhet i Norge. Tidsskr Nor Legeforen, 125 (5), 560-563. 